\title{
ALPHA-1-ANTITRYPSIN DEFICIENCY AND LIVER DISEASE
}

\author{
G. H. Millward-Sadler
}

Department of Pathology. Southampton General Hospital. Southampton. England.

In this review article only the liver disease associated with alpha-1-antitrypsin deficiency will be considered. For the well recognised association with lung disease the review by Mittman (1972) is recommended. Various other disease associations have been suggested but the relationships are tenuous and beyond the scope of this article: readers are referred to the original articles (Andre et al 1974, Cox \& Huber 1976, Geddes et al 1977, Miller \& Kuschner 1969, Moroz et al 1976, Novis et al 1975, Sjoblom \& Wollheim 1977, Triger et al 1976).

\section{STRUCTURE, FUNCTION AND GENETICS OF ALPHA-1-ANTITRYPSIN}

Alpha-1-antitrypsin (A1AT) is a glycoprotein (molecular weight 55,000) which is thought only to be synthesised by the liver. The carbohydrate content is approximately $12 \%$ of the molecule and includes galactose, mannose, $\mathrm{N}$-acetyl glucosamine and sialic acid. This glycoprotein forms $90 \%$ of the alpha-1 globulin in serum and is present in a concentration of $2 \mathrm{G} /$ litre or more in normal subjects. Very high serum levels may be found in conditions of stress as it is, like fibrinogen, an acute phase reactant protein. Its function has not been established in the body with certainty but in vitro it is a major inhibitor of proteases. Variants of alpha-1-antitrypsin can be recognised by differing protein mobility on electrophoresis and the faster moving proteins are identified by the earlier letters of the alphabet with the slowest moving variant labelled $Z$. These alleles are described by the letters $\mathrm{Pi}$ (for protease inhibitor) followed by the letter describing the particular variant. The variants are inherited in an autosomal codominant manner and the common phenotype is termed PiMM.

At least 24 alleles have been identified of which the most important clinically are $S$ and $Z$. Patients who are homozygous for $S$ have serum levels approximately $50 \%$ of normal while homozygosity for $Z$ is associated with serum levels of approximately $10 \%$ of normal. There is also a rare variant termed $\mathrm{Pi}$ null which has no detectable alpha-1-antitrypsin in the serum and is thought to be due to a gene deletion (Talamo, et al 1973). Extensive population studies conducted in different countries have revealed quite significant variations in the frequency of certain pheriotypes, (Cook 1975, Fagerhol 1976, Pierce et al 1975 Vandeville et al 1972). The PiMM phenotype occurs in 80 to $95 \%$ of a population and is associated with the normal serum levels of $2 \mathrm{G} /$ litre or more. Negroes and American Indians have a very high incidence of PiMM and a low incidence of $\mathrm{PiZ}$. Peoples of Spanish origin have a very high incidence of $\mathrm{PiS}$, while the highest incidence of $\mathrm{PiZ}$ occurs in Scandinavia and the U.K. The incidence of the $S, M$ and $\mathrm{Z}$ alleles are given in Table 1 , but approximately $0.06 \%$ of the population of Northern Europe are homozygous for $\mathrm{Z}$ and have a frequency of approximately $2.4 \%$ for the allele (Laurell \& Sveger 1975, Sveger 1976). 
Finger printing techniques using cyanogen bromide have demonstrated differences in the aminoacid composition of the polypeptide chains of PiM, PiZ and PiS, (Jeppsson 1976, Yoshida et al 1976, Owen \& Carrell 1976). PiZ appears to have one lysine residue more and one glutamic acid residue less than PiM while PiS seems to have one valine residue more and one glutamic acid residue less than PiM. These substitutions result in considerable electrical charge changes and it is postulated that the position of the substitution along the polypeptide chain may be close to and interfere with the attachment of carbohydrate side chains, in particular sialic acid. This would then explain why there is a reduced amount of sialic acid on the $\mathrm{PiZ}$ variant in the serum compared to the equivalent PiM and as glycosylation is thought to be necessary for protein secretion it would also explain the low total serum values in these variants.

Table 1

Incidence of Phenotypes of $A 1 A T$ in various countries

\begin{tabular}{llll}
\hline & M & S & Z \\
\hline U.K. & 93 & 5 & 1.4 \\
\hline Sweden & 92 & 3 & 2.4 \\
\hline U.S.A. Black & 98 & 1 & 0.5 \\
\hline White & 95 & 3.4 & 1.2 \\
\hline France & 96 & 0.25 & 1.6 \\
\hline Spain & 92 & 7 & 0.6 \\
\hline Japan & 87 & 11 & 1.2 \\
\hline
\end{tabular}

\section{MEASUREMENT OF SERUM ALPHA-1-ANTITRYPSIN}

The deficiency was originally detected because of the absence of an alpha-1 globulin peak on a paper electrophoretic strip. This simple test is unfortunately not reliable because only the most severely deficient patients will be identified in this manner and because any diffuse increase in globulins may conceal alpha-1 globulin deficiency. Most methods are now immunochemical and the most commonly used method is a single radial immunodiffusion technique for which agar gel plates and quantitative standards are widely available commercially, (Mancini, et al 1965). We preferred, after a comparative study, to use an alternative technique of electroimmunoassay (Triger, et al 1976). The identification of the phenotype can either be performed by acid starch gel electrophoresis, (Fagerhol \& Laurell 1965), antigen-antibody electrophoresis (Laurell 1965) (which is usually reserved for the more difficult cases) or, more recently, by isoelectric focusing on polyacrylamide gel slabs, (Allen et al 1974). The latter appears to be a much simpler procedure and is quick to perform. It also appears to be more sensitive as Kueppers (1976) was able to subdivide the $\mathbf{M}$ phenotype into $M$ and $M 1$ by this technique. Nonetheless, interpretation of the various patterns produced by these techniques is difficult and there are considerable technical problems so that the phenotyping should be centralised in a specialised centre possessing both considerable experience and adequate control sera. 


\section{CLINICAL FEATURES}

One of the most strange features of $A 1 \mathrm{AT}$ deficiency and liver disease is its pleomorphism in clinical presentation. At the one extreme of life it occurs as one of the most common causes of the Neonatal Hepatitis Syndrome (Cottrall et al 1974) or can present as a hepatic failure due to an end-stage cirrhosis in an elderly person who has been completely asymptomatic and apparently healthy until the onset of his terminal illness.

\section{Neonatal Hepatitis}

A1AT deficiency appears to be a significant cause of neonatal hepatitis accounting for up to $40 \%$ of cases, (Aagenaes et al 1972, Cottrall et al 1974, Moroz et al 1976). Retrospective analysis in several series has shown that the birth weight of these children tends to be below normal and that the typical symptoms of jaundice, pale stools and dark urine usually appear between one and six weeks after birth, (Sveger 1976). Jaundice may occasionally be present at birth or develop as late as two to three months after birth. In the majority of cases jaundice is transient and the liver function tests, which usually show elevations of the serum bilirubin, aspartate transaminase (AST) and alkaline phosphatase, may all return to normal though hepatosplenomegaly usually persists if careful clinical examination is performed. Certain criteria indicate an adverse prognosis (Cottrall et al 1974). These include the development of jaundice early in the neonatal period, persistence of the jaundice, greater maximum abnormalities in standard liver function tests, and persistent elevation of the AST during the second year of life. Cirrhosis during early childhood is more common in association with these features. Some prognostic features can also be gleaned from liver biopsies and these will be discussed later. Clinical presentation in the neonatal period occurs mostly in children with the homozygous $\mathrm{PiZ}$ defect but there are individual reports in the literature showing an association with the SZ and MZ phenotypes (Elema et al 1975, Wilkinson et al 1974). It must be emphasised that not all children with homozygous PiZ develop neonatal hepatitis. In a comprehensive study in Sweden (Sveger 1976) over 95\% of all infants born in a 2 year period were screened during the first few days of life. Of 200,000 babies screened, 120 were homozygous $\mathrm{Z}$ but only 22 of these developed jaundice with abnormal liver function during the first 3 months of life. This may under estimate the true incidence of liver disease since an elevated AST was reported in 44 out of 84 of all infants screened at 3 months and in 36 of the 60 homozygous $Z$ infants screened at 6 months. Nonetheless, it does indicate the proportion of children who presented with clinical abnormalities. Further studies in this group should define the probability of developing neonatal hepatitis, childhood cirrhosis, adult cirrhosis, pulmonary emphysema, other associated disease or of having a normal life span. Unfortunately, in this survey only homozygotes were reliably detected and, as will be indicated later, there is accummulating evidence that the heterozygote $\mathrm{P} i \mathrm{Z}$ may develop liver disease in adult life.

\section{Cbildbood Cirrbosis}

Most cases of A1AT deficiency presenting as neonatal hepatitis syndrome make a full clinical recovery but a proportion then present in later childhood with cirrhosis either without intermission or after an asymptomatic interval of time. Conversely, of children presenting with cirrhosis associated with A1AT deficiency at least $50 \%$ have no antecedent history of jaundice during the first few months of life (Aagenaes et al 1972). Although neonatal jaundice due to A1AT deficiency is well documented, very 
Table 2

Liver disease and A1AT Globules *

\begin{tabular}{|c|c|c|c|}
\hline \multirow{2}{*}{ Phenotype } & \multirow{2}{*}{$\mathrm{N}^{0}$} & \multicolumn{2}{|c|}{ Pathology } \\
\hline & & Fibrosis & Cirrhosis \\
\hline $\mathrm{ZZ}$ & 5 & 2 & 3 \\
\hline $\mathrm{MZ}$ & 6 & 1 & 5 \\
\hline $\mathrm{SZ}$ & 1 & 0 & 1 \\
\hline SS & 1 & 1 & 0 \\
\hline MS & 1 & 0 & 1 \\
\hline Other * & 4 & 2 & 2 \\
\hline Total & 18 & 6 & 12 \\
\hline
\end{tabular}

* MM phenotype , 1 'atypical' phenotype who died of carcinomatosis before this could be further analysed and 2 lost to follow-up.

** 10 cases of liver disease with globules but due to other causes have been excluded. These are 8 alcoholics, 1 primary biliary cirrhosis, and 1 Budd-Chiari Syndrome $2^{\circ}$ to renal carcinoma occluding the inferior vena cava

\section{PATHOLOGY}

The pathology of the liver in homozygous $\mathrm{PiZZ}$ deficiency is characterised by a constant presence within hepatocytes of globules which are strongly Periodic acid-Schiff positive and diastase resistant. These acidophilic globules are not regularly identified on routine haematoxylin \& eosin sections as they merge with general cytoplasmic staining. It is therefore mandatory for diastase-PAS stains to be performed on all cases of idiopathic liver disease and preferably as a routine on all liver biopsies. Globules are most easily found in hepatocytes adjacent to portal tracts or abnormal fibrous tissue. They may either be single large globules that distend the cytoplasm and displace the nucleus to one side (Fig. 1) or, more commonly and characteristically multiple small globules within the cytoplasm (Fig. 2). Globules can also be demonstrated in heterozygous $\mathrm{MZ}$ patients but the globules are both smaller in size and in number and may be found only in a few hepatocytes. These hepatocytes are usually periportal in distribution but in the heterozygote not all portal tracts necessarily are involved. Using the diastase PAS stain occasional cells in peripheral bile ductules with low cuboidal epithelium sometimes contain globules.

Histochemically these globules can be identified as a glycoprotein and antigenically are identical to $A 1 A T$ by both immunofluorescence and immunoperoxidase techniques (Triger et al 1975). Characteristically the rim of the globule is more strongly stained than the contents in these immunological techniques. (Fig. 3). In the electron microscope dilated saccular endoplasmic reticulum containing. amorphous electron dense material can be found. Both rough and smooth components of endoplasmic reticulum are involved but the earliest and frequently the greatest accumulation appears to occur in the smooth endoplasmic reticulum (Fig. 4). The Golgi Apparatus is not involved. Immunoelectron-microscopy has confirmed that this amorphous material is A1AT (Feldman et al 1974).

These PAS positive globules almost invariably implicate the $\mathrm{Z}$ phenotype but do occasionally occur in association with the $S$ phenotype. They have also been described in association with an abnormal A1AT which in the homozygote is associated with extreme deficiency in the serum but in the heterozygote has normal serum levels and electrophoretically migrates as PiM (Cox 1975, Lieberman et al 1976). The globules must also be differentiated from those weakly stained PAS positive globules occurring 


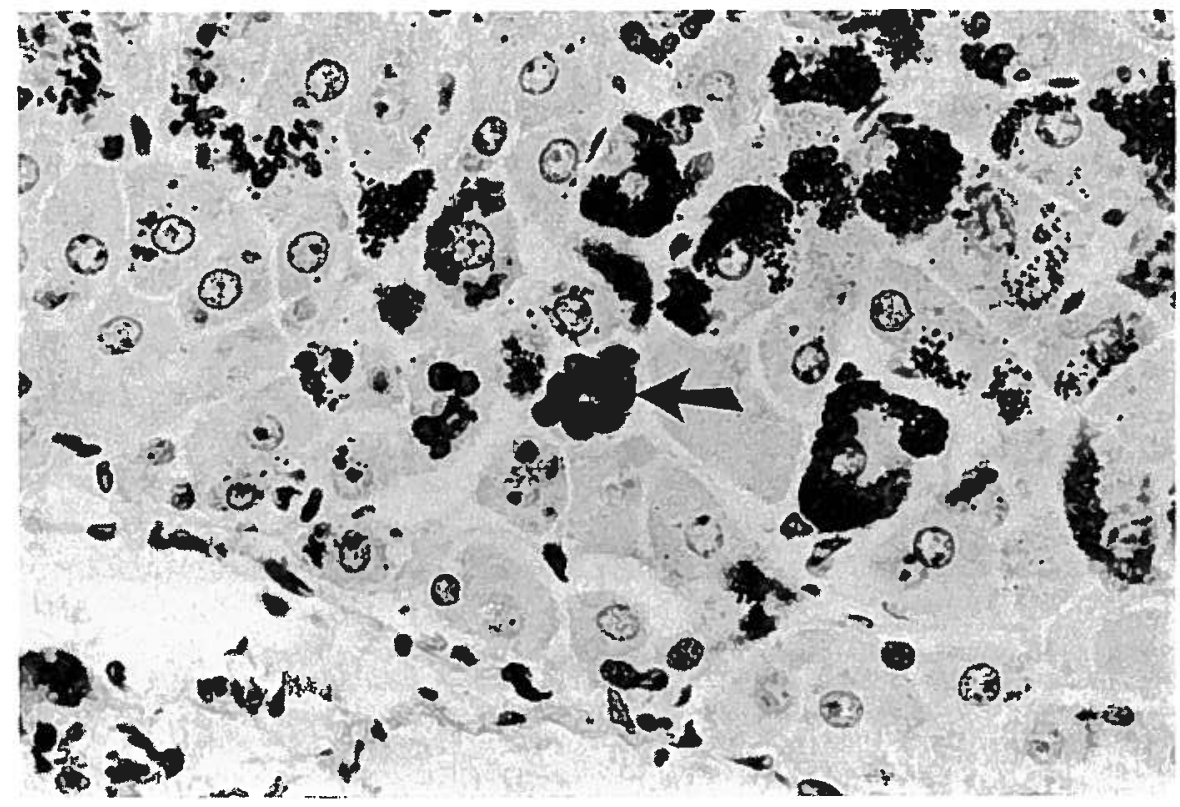

Fig. 3 - Portal tract bottom left with periportal bepatocytes positinely stained by tbe P.A.P immunoperoxidase technigue using antibody to buman alpha-1-antitrypsin. The larger globules bav'e an easily identifiable rim (arrou's) and with better resolution the same feature can be identified in the smaller 'granules' clustered witbin some of the bepatocytes.

(trypsin-immunoperexidase technique $\times 500)$

in hepatocytes around zones of necrosis or other hepatocellular damage. These globules also contain A1AT but appear to represent a temporary accumulation of the protein within the hepatocyte and disappear with recovery of the cell from the insult. They rarely cause diagnostic confusion as they are much more pale staining, and are rarely periportal in distribution.

Despite these exceptions we always regard the presence of diastase-resistant PAS positive globules in hepatocytes as evidence of A1AT deficiency until proved otherwise, and then we proceed to at least immunoperoxidase identification in the liver biopsy with serological confirmation of the phenotype and perform family studies whenever possible. It should be noted that serum levels of A1AT in the heterozygote can reach the normal range particularly in conditions of stress. 


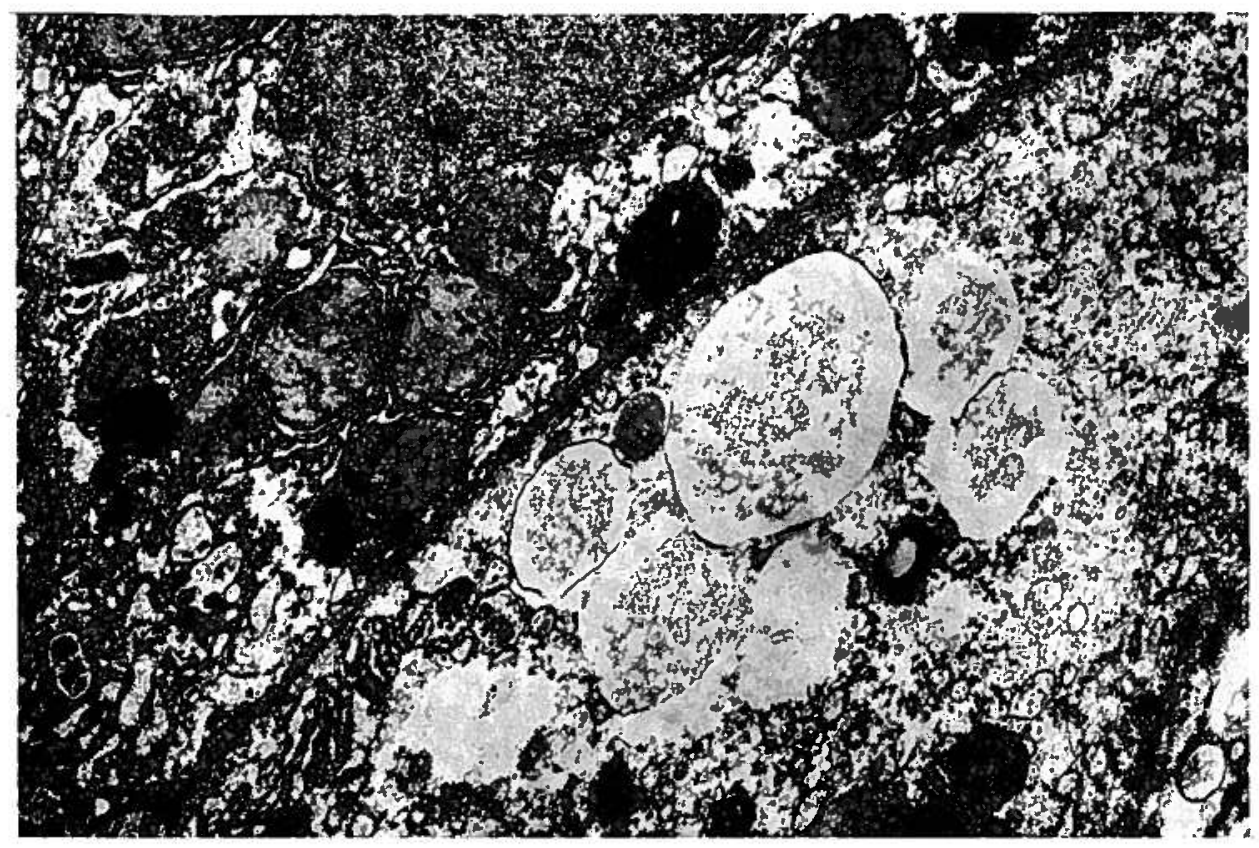

Fig. 4-Plasma membranes of two adjacent bepatocytes run obliquely across the field. Endoplasmic reticnlum in top left bepatocyte is slightly dilated but lacks the dramatic globular distension seen along the plasma membrane of the bottom right bepatocyte.

(Lead citrate and uranyl acetate $\times 12,000$ ).

\section{Pathology in specific age groups}

Neo-natal bepatitis syndrome - Macroscopically the liver is enlarged and green and may be smooth or finely granular. Associated hypoplasia of the biliary tree has occasionally been noted but is uncommon (Christen et al 1975, Burke et al 1976). The histological manifestations vary from classical neonatal hepatitis to a pattern resembling biliary obstruction (Talbot \& Mowat 1975). This latter pattern is commonly misdiagnosed as intrahepatic biliary hypoplasia. It is important to identify the presence of PAS positive globules in periportal hepatocytes which are present from at least one month of age (Burke et al 1976, Hadchouel \& Gautier 1976). This can be difficult when there is an abundance of PAS positive ceroid pigment in Kupffer cells. In this respect the immunoperoxidase technique will clearly demonstrate the globules with their intensely stained rim and confirm the diagnosis. Prognostic features from biopsies have been recorded by Hadchouel \& Gautier (1976). They describe intrahepatic biliary hypoplasia in five of their 15 cases of A1AT deficiency presenting in the neonatal period and this feature appeared to be associated with relatively long asymptomatic survival into the late teens at the time of reporting. Conversely, proliferation of bile ductules at the edges of portal tracts was not a feature associated with this paucity but rather was an adverse sign indicating the presence of fibrosis sometimes sufficiently severe to be termed cirrhosis. 
Pathology of childhood cirrhosis

Detailed pathological accounts are exceptional and usually confined. to a description of the globules and the overall pattern of cirrhosis. The most frequent pattern recorded is of micronodular cirrhosis but only rarely have sequential changes through to autopsy been documented. One such example (Asarian et al, 1975) showed a conversion from micronodular cirrhosis to macronodular cirrhosis over a period of 5 years.

\section{Adult Liver Disease}

Liver biopsies from adults may be normal apart from the presence of globules, show fibrosis or cirrhosis or show features of another pathological process with globules as an additional factor. The fibrosis expands portal tracts irregularly and not every tract is necessarily involved. Globules are most prominent against abnormal tracts. When present the cirrhosis is most frequently macronodular and the irregular nature of cirrhosis means that on a liver biopsy the presence of abnormal fibrosis does not definitively exclude cirrhosis at the time of biopsy. So far no bile duct hypoplasia has been described in cases of adult cirrhosis and we have not noted this feature in any of our cases, despite careful search. Florid bile ductular hyperplasia has been noted but only has been described in the presence of an advanced cirrhosis (Gherardi 1971). Apart from the presence of globules piecemeal necrosis may be identified in the biopsy (Triger et al 1975) and it is in these areas that the globules are frequently most prominent. We have been unable to demonstrate any other consistent feature that could not be attributed to the cirrhosis rather than to the enzyme deficiency. Thus, Mallory bodies may be present in some of the more advanced cases of cirrhosis, irbn is only present in small amounts and Hepatitis B surface antigen has never been found in any of our patients although cases of chronic hepatitis B infection with AlAT deficiency have been described (Blenkinsopp \& Haffenden 1977).

\section{Hepatoma}

Hepatoma has been described as a complication of the liver disease of A1AT deficiency. There are no specific gross or microscopic features of the hepatoma that distinguish them from those occurring with other associations. We have only had one patient with hepatoma in our series (Triger et al 1975 and personal observations); this was associated with probable heterozygous deficiency. This is in contrast to Berg and Eriksson (1972) who found two cases of hepatocellular carcinoma and one cholangio-carcinoma amongst 8 patients with cirrhosis or fibrosis and $\mathrm{ZZ}$ deficiency. Furthermore, in a retrospective review of 75 liver cell carcinomas these authors also found 7 cases in which the characteristic morphology of A1AT deficiency was demonstrable in the liver. Subsequently the Swedish group has reported 9 patients with cirrhosis associated with the PiZ phenotype, in whom 6 hepatomas have occurred (Eriksson \& Hagerstrand 1974). However, neither Theodoropoulos, et al (1976) in Greece nor Charlionet and colleagues (1976) in West Africa have found any increased incidence of AlAT deficiency in studying patients with hepatic carcinoma and cirrhosis.

\section{PATHOGENESIS OF LIVER DISEASE}

The variable rate of progression of liver disease, where some homozygous children present with neonatal jaundice and rapidly progress to cirrhosis and death but other patients with equivalent deficiency never apparently develop clinical disease, is an enigma. 
Many explanations have been postulated but none are satisfactory. In heterozygous $\mathrm{MZ}$ states the absence of liver disease in the presence of globules has been used to argue that the globules themselves are not toxic to hepatocytes and so, consequently, in the long term are not implicated in the pathogenesis of the cirrhosis. Unfortunately liver disease does develop in the heterozygote (Triger et al 1975) albeit more slowly and less predictably, so that this possibility is not excluded. The serum level of A1AT, although possibly incriminated in the pathogenesis of the lung disease, does not influence the liver disease. Patients who are $\mathrm{Pi}$ null (possible due to a gene delection) do not have detectable A1AT in their serum and do not have either globules of A1AT in their hepatocytes or any clinical, laboratory or histopathological evidence of liver disease (Talamo et al 1973).

As commonly happens with such problems, ancillary factors combining with A1AT deficiency to produce cirrhosis have been postulated (Aagenaes et al 1974) and it is certainly reasonable to speculate that, for instance, in these patients alcohol will more readily produce cirrhosis at lower levels of intake and over shorter periods of time. So far the evidence is lacking: alcohol (Morin et al 1975) chronic active hepatitis and primary biliary cirrhosis (Kueppers et al 1976), iron and HBs Ag (Triger et al 1976) are not apparently related. Other biochemical abnormalities within the hepatocyte may be incriminated. The presence of sialyl tranferase deficiency in one patient (Kuhlenschmidt et al 1974) has not been confirmed in additional patients (Eriksson \& Larsson 1975) but obviously other biochemical possibilities have not been exhausted.

A further possibility remains: Sharp (1976) suggested that the normal resolution of inflammatory reactions resulting from bacteria and toxins reaching the liver in portal venous blood may be impaired in the absence of A1AT. The prolonged inflammation would then stimulate fibrogenesis and cirrhosis could develop following several such episodes. More recently it has been demonstrated that A1AT is present in normal Kupffer cells and that in homozygous deficiency these macrophages lack A1AT even when the small amounts in the serum can be detected (personal observations). The role of the Kupffer cell in the pathogenesis of the cirrhosis therefore remains to be elucidated but even if it should prove to be important it is still difficult to explain satisfactorily the mechanism of the jaundice in the neonatal infant.

\section{TREATMENT}

Treatment currently available for this condition is unsatisfactory. A trial of phenobarbitone to try and induce increased enzyme turnover was unsuccessful (Porter et al 1972, Sharp 1976) as was treatment with corticosteroids (Porter et al 1972). Replacement therapy is impractical as the half life of the enzyme in the serum is only 4-6 days (Makino \& Reed 1970). Mostly treatment is confined to genetic counselling of patients with children who have the deficiency and to the control of symptoms and complications of the cirrhosis.

Bleeding oesophageal varices have been treated by portacaval anastomosis and survival for up to ten years after the initial variceal bleeding has been recorded (Triger \& Millward-Sadler 1979).

Liver transplantation offers the prospect of a cure not only of the liver disease but also of the enzyme deficiency. Two cases have been reported: one survived only a few days (Sharp 1976) and the other for two years (Putman et al 1977). The serum phenotype in the recipient changes to that of the donor liver. The lack of satisfactory alternative forms of treatment suggests that transplantation may become the treatment of choice for progressive liver disease in the juvenile or young adult and that this may depend mostly upon advances in the techniques of liver transplantation and the availability of this facility to a community. 


\section{REFERENCES}

AAGENAES O, MATLARY A, ELGJO K, MUNTHE E \& FAGERHOL M: (1972) Neonatal Cholestasis in alAT deficient children: clinical, genetic, histological and immunohistochemical findings. Acta Paediatrica Scandinavica, 61, 632-642.

AAGENAES O, FAGERHOL M, ELGJO K, MUNTHE E \& HOVIG T: (1974) Pathology and pathogenesis of liver disease in $\alpha 1 \mathrm{lT}$ deficient individuals. Postgraduate Medical Journal, 50, 365-375.

ALLEN RC, HARLEY RA \& TALAMO, RC: (1974) A new method for determination of $\alpha 1$ AT phenotypes using isoelectric focusing on polyacrylamide gel slabs. American Journal of Clinical Pathology, 62, 732 -739 .

ANDRÉ F, ANDRÉ C, LAMBERT R \& DESLOS F: (1974) Prevalence of $\alpha 1$ AT deficiency in patients with gastric or duodenal ulcer. Biomedicine (Express), 21, 222-224.

ASARIAN J, ARCHIBALD RW \& LIEBERMAN J: (1975) Childhood cirrhosis is associated with $\alpha$ lAT deficiency. A genetic biochemical and morphological study. Journal of Pediatrics, 86, 844-850.

BERG NO \& ERIKSSON S: (1972) Liver disease in adults with $\alpha 1$ AT deficiency. New England Journal of Medicine, 287, 1264-1267.

BLENKINSOPP WK \& HAFFENDEN GP: (1977) $\alpha 1$ AT bodies in the liver. Journal of Clinical Pathology, 30, $132-137$.

BRAND B, BEZAHLER GH \& GOULD R: (1974) Cirrhosis and Heterozygous FZ $\alpha 1$ AT deficiency in an adult. Case report and review of the literature. Gastrenterology, 66, 264-268.

BURKE JA, KIESEL JL \& BLAIR JD: (1976) $\alpha 1$ AT deficiency and liver disease in children. American Journal of Diseases of Cbildren,130, 621-629.

CAMPRA JL, CRAIG JR, PETERS RL \& REYNOLDS TB: (1973) Cirrhosis associated with partial deficiency of $\alpha$ IAT in an adult. Annals of Internal Medicine, 78, 233-238.

CHARLIONET R, MARTIN JP, SESBOUÉ R \& ROPARTZ C: (1976) Is there a relationship between alpha- I-antitrypsin PiMZ phenotype and hepatoma? Biomedicine (Express) 25 (4). 126.

CHRISTEN H, BAU J \& HALSBAND H: (1975) Hereditary $\alpha 1$ AT deficiency associated with congenital extra-hepatic bile duct hypoplasia. Klinische Wochenschrift, 53. 90-91.

COOK PJL: (1975) The genetics of $\alpha 1 A T$ : a family study in England and Scotland. Annals of Human Genetics (London), 38, 275-287.

COTTRALL K, COOK PJ \& MOWAT AP: (1974) Neonatal hepatitis syndrome and $\alpha$ IAT deficiency: an epidemiological study in Southeast England. Postgraduate Medical Journal, 50, 376-380.

COX DW: (1975) A new deficiency allele of $\alpha 1$ AT: PiM Malton. In Protides of Biological Fluids (Ed.) Peeters. H. Vol. 23, pp 375-378, New York: Pergamon Press.

COX DW \& HUBER O: (1976) Rheumatoid arthritis and $\alpha 1$ IAT.Lancet $i, 1216-1217$.

CRUZ M, MOLINA JA, PEDROLA D \& MUNOZ LOPEZ F: (1975) Cirrhosis and heterozygous $\alpha 1$ AT deficiency in a 4 year old girl. Helvetica Paediatrica Acta, 30, 501-507.

ELEMA JD, BOERSMA R \& REERINK-BRONKERS E: (1975) Proceedings: clinical observations and histopathology of the liver in infants and children with $\alpha 1$ AT deficiency. Archives of Diseases in Childhood. 50,663 .

ERIKSSON 5 \& HAGERSTRAND I: (1974) Cirrhosis and malignant hepatoma in $\alpha$ IAT deficiency. Acta Medica Scandinavica 195, 451-458.

ERIKSSON S \& LARSSON C: (1975) Role of sialyltransferase in $\alpha$ l AT deficiency. New England Journal of Medicine, 292, 925-926.

FAGERHOL MK: (1976) The genetics of $\alpha$ IAT and its implications. Postgraduate Medical Journal, 52, (Supll. 2), 73-83.

FAGERHOL MK \& LAURELL CB: (1967) The polymorphism of prealbumins and $\alpha 1$ antitrypsin in human sera. Clinica Cbimica Acta, 16, 199-203.

FELDMAN G, BIGNON J, CHAHINIAN P, DEGOTT C \& BENHAMOU JP: (1974) Hepatocyte ultrastrucr tural changes in $\alpha$ lAT deficiency. Gastroenterology, 67 1214-1224.

GEDDES DM, WEBLEY M, BREWERTON DA, TURTON CW, TURNER-WARWICK M, MURPHY AH \& MILFORD WARD A: (1977) $\alpha$-1-antitrypsin phenotypes in fibrosing alveolitis and rheumatoid arthritis. Lancet ii 1049-1050.

GHERARDI GJ: (1971) $\alpha$ IAT deficiency and its effect on the liver. Human Patbology, 2, 173-175.

HADCHOUEL M \& GAUTIER M: (1976) Histopathologic study of the liver in the early cholestatic phase of $\alpha 1 \mathrm{AT}$ deficiency. Journal of Pediatrics, 89, 211-215.

JEPPSSON JO: (1976) Amino acid substitution glu-lys in $\alpha$ i AT PiZ FEBS Letters, 65, $195-197$.

KUEPPERS F: (1976) $\alpha 1$ AT M1 - a new common genetically determined variant. American Journal of Human Genetics, 28 (4) 370-377.

KUEPPERS F, DICKSON ER \& SUMMERSKILL WHJ: (1976) $\alpha 1 \mathrm{AT}$ phenotypes in chronic active liver disease and primary biliary cirrhosis. Mayo Clinic Proceedings, 51 (5), 286-288.

KUHLENSCHMIDT MS, YUNIS EJ, IAMMARINO RM, TURCO SJ, PETERS SP \& GLEW RH: (1974) Demonstration of sialyltransferase deficiency in the serum of a patient with $\alpha 1 \mathrm{AT}$ deficiency and cirrhosis. Laboratory Investigations 31, 413-419.

LAURELL CB: (1965) Effect of neuraminidase, acetone and chloroform on $\alpha 1$ AT. Scandinavian Journal of Clinical and Laboratory Investigation, 17, 297-298. 
LAURELL CB \& SVEGER T: (1975) Mass screening of newborn Swedish infants for $\alpha$ IAT deficiency. Ame. rican Journal of Human Genetics, 27, 213-217.

LIEBERMAN J, GAIDULIS L \& KLOTZ SD: (1976) A new deficient variant of $\alpha$ 1AT (M. Duarte). American Review of Respiratory Diseases, 113, 31-36.

MAKINO S \& REED CE: (1970) Distribution and elimination of exogenous $\alpha$ lAT. Journal of Laboratory and Clinical Medicine, 75, 742-746.

MANCINI G, CARBONARA AO \& HEREMANS JF: (1965) Immunochemical quantitation of antigens by single immunodiffusion. Immunochemistry, 2, 235-254.

MILLER F \& KUSCHNER M: (1969) $\alpha 1 A T$ deficiency emphysema, necrotizing angiitis and glomerulo-nephritis. American Journal of Medicine, 46, 615-623.

MITTMAN C: (1972) Pulmonary Emphysema and Proteolysis. London: Academic Press.

MORIN T, MARTIN JP, FELDMANN G, RUEFF B, BENHAMOU JP \& ROPARTZ C: (1975) Heterozygous $\alpha 1 \mathrm{AT}$ deficiency and cirrhosis in adults, a fortuitous association. Lancet i, 250-251.

MOROZ SP, CUTZ E, COX DW \& SASS-KORTSAK A: (1976) Liver disease associated with $\alpha$ I AT deficiency in childhood. Journal of Pediatrics, 88, 19-25.

NOVIS BH, YOUNG GO, BANK S \& MARKS IN: (1975) Chronic pancreatitis and $\alpha 1$ AT. Lancet ii, 748-749.

OWEN MC \& CARRELL RW: (1976) $\alpha$ 1AT: molecular abnormality of S variant. Britiśn Medical Journal $i$, $130-131$.

PIERCE JA, ERADIO B \& DEW TA: (1975) Antitrypsin phenotypes in St. Louis. Journal of the American Medical Association, 231, 609-612.

PORTER CA, MOWAT AP, COOK PJ, HAYNES DW, SHILKIN KB \& WILLIAMS R: (1972) 1 Antitrypsin deficiency and neonatal heparitis. Britis'b Medical Journal iii, 435-439.

PUTMAN CW; PORTER KA, PETERS RL, ASCHCAVAI M, REDEKER AG \& STARZL TE: (1977) Liver replacement of $\alpha 1$ antitrypsin deficiency. Surgery, 81, 258-261.

SHARP HL: (1976) $\alpha 1$ antitrypsin deficiency. Hospital Practice 6. 83-96.

SJOBLOM KG \& WOLLHEIM FA: (1977) $\alpha 1$ antitrypsin phenotypes and rheumatic diseases. Lancet. ii 41-42.

SVEGER T: (1976) Liver disease in $\alpha 1$ AT deficiency detected by screening of 200,000 infants. New England Joumal of Medicine, 294, 1316-1321.

TALAMO RC, LANGLEY CE, REED CE \& MAKINO S: (1973) $\alpha 1$ AT deficiency: a variant with no detectable $\alpha 1$ antitrypsin. Science (New York) 181, 70-71.

TALBOT IC \& MOWAT AP: (1975) Liver disease in infancy: histological teatures and relationship to $\alpha 1$ AT phenotype. Journal of Clinical Patbology, 28, 559-563.

THEODOROPOULOS G, FERT AKIS A, ARCHIMANDRITIS A, KARPORDELIS C \& ANGELOPOULOS B: (1976) $\alpha 1 \mathrm{AT}$ phenotypes in cirrhosis and hepatoma. Acta Hepatogastroenterologica (Stuttgart), 23 (2), 114-117.

TRIGER DR, MILLWARD-SADLER GH: (1979) Alpha-i-antitrypsin deficiency and liver disease. In 'Liver and Biliary Disease' eds. WRIGHT R, ALBERTI KGMM, KARRAN S \& MILLWARD-SADLER GH, Holt-Saunders CO. Led. Eastbourne 805-21.

TRIGER DR, MILLW ARD-SADLER GH, CZAYKOWSKI AA, TROWELL J \& WRIGHT R (1976) $\alpha 1 A T$ deficiency and liver disease in adults. Quarterly Journal of Medicine, 45, 351-372.

VANDEVILLE D, MARTIN JP, LEBRETON JP \& ROPARTZ C: (1972) Le système Pidans les populations normande et amérindienne. Revue Francaise de Transfusion, 15. 213-218.

WILKINSON EJ, RAÄB K, BROWNING CA \& HOSTY TA: (1974) Familial hepatic cirrhosis in infants associated with $\alpha 1 \mathrm{AT}$ SZ phenotype. Journal of Pediatrics, 85, 159-164.

YOSHIDA A, LIEBERMAN J, GAIDULIS L \& EWING C: (1976) Molecular abnormality of human $\alpha$ IAT variant, $\mathrm{PiZZ}$ associated with plasma activity deficiency. Proceedings of the National Academy of Science of the United States of America, 73, 1324-1328.

Address for reprints: G. H. Milluard-Sadler Department of Patbology

Soutbampton General Hospital

Tremona Roud

Soutbampton $5094 X Y$

England 